\title{
PARQUE ESTADUAL DO IBITIPOCA (PEI-MG): CONSIDERAÇÕES SOBRE SUA BIODIVERSIDADE E GEODIVERSIDADE
}

\author{
Lilian Carla Moreira Bento ${ }^{1}$
}

\author{
Sílvio Carlos Rodrigues ${ }^{2}$
}

\begin{abstract}
RESUMO
O Parque Estadual do Ibitipoca é uma unidade de conservação integral, encravada na Serra de Ibitipoca, sudoeste de Minas Gerais, entre os municípios de Lima Duarte, Bias Fortes e Santa Rita do Ibitipoca, a cerca de $300 \mathrm{~km}$ de distância ao sul da capital mineira, Belo Horizonte e cerca de $240 \mathrm{~km}$ ao norte da cidade do Rio de Janeiro. Este parque, assim como a maioria que existe no Brasil, foi criado tendo como justificativa a necessidade premente de se proteger a biodiversidade. $\mathrm{O}$ objetivo desse trabalho é estimular uma visão integrada da natureza, ressaltando que a biodiversidade nada mais é que o resultado da geodiversidade, a partir do estudo de caso do PEI, o qual se refere a uma vertente trabalhada na pesquisa de doutorado do autor principal. A metodologia empregada para atingir esse objetivo pode ser resumida em revisão bibliográfica pertinente ao tema, trabalhos de campo na área de estudo e trabalhos de gabinete, momento de análise e integração dos dados obtidos, com elaboração de textos, perfis e mapas. Diante da metodologia empregada depreende-se que, apesar dos argumentos usados para criação do PEI serem, a sua maioria, pautados na importância da biodiversidade, é a geodiversidade a grande responsável por esta, devendo; portanto, ser também valorizada e divulgada.
\end{abstract}

PALAVRAS-CHAVE: Unidades de conservação. Aspectos bióticos e abióticos.

\section{STATE PARK OF IBITIPOCA (PEI-MG): CONSIDERATIONS ABOUT ITS BIODIVERSITY AND GEODIVERSITY}

\begin{abstract}
The state park of Ibitipoca is a whole conservation unit, wedged in Ibitipoca Hill, southeast of Minas Gerais, between the towns of Lima Duarte, Bias Fortes and Santa Rita do Ibitipoca, about $300 \mathrm{~km}$ to the South from Minas Gerais state capital and about $240 \mathrm{~km}$ to the North from the city of Rio de Janeiro. This park, as most of the ones existing in Brazil, was created with a view to justify the urgent need to protect biodiversity. The objective of this work is to stimulate a whole view of nature, highlighting that biodiversity is nothing more than the result of geodiversity, from the case study of PEl, which refers to a part worked in the doctorate research of the main author. The methodology used to reach this objective may be resumed in bibliographical revision about the theme, field works in the study area as well as office work, an analysis moment and integration of the data collected, with the elaboration of profiles and maps. Before such methodology one gathers that, despite the arguments used for the creation of
\end{abstract}

\footnotetext{
${ }^{1}$ Doutora em Geografia, Prof. Substituta, Universidade Federal de Uberlândia. liliancmb@yahoo.com.br 2 Doutor em Geografia. Prof. Universidade Federal de Uberlândia. silgel@ufu.br
} 
PEI being, mostly, based upon the importance of the biodiversity, it is the geodiversity the greatest responsible for that, and it must have great value and publicizing.

KEY-WORDS: Conservation units. Biotic and abiotic aspects.

\title{
PARQUE ESTADUAL DEL IBITIPOCA (PEI-MG): CONSIDERACIONES SOBRE LA SUYA BIODIVERSIDAD Y GEODIVERSIDAD
}

\begin{abstract}
RESUMEN
El Parque Estadual del Ibitipoca es una unidad de conservación integral, enclavada en la Sierra del Ibitipoca, sudoeste de Minas Gerais, entre los municipios de Lima Duarte, Bias Fortes y Santa Rita del Ibitipoca, cerca de $300 \mathrm{~km}$ de distancia al Sur de la capital mineira, Belo Horizonte y alrededor de 240 $\mathrm{km}$ al Norte de la ciudad del Rio de Janeiro. Este parque, así como la mayoría que existe en Brasil, fue creado teniendo como justificación la necesidad urgente de se proteger la biodiversidad. El objetivo de ese trabajo es estimular una visión integrada de la naturaleza, resaltando que la biodiversidad nada más es que el resultado de la geodiversidad, a partir del estudio de caso del PEl, lo qual se refiere a una vertiente trabajada en la pesquisa de doctorado del autor principal. La metodología empleada para alcanzar ese objetivo puede ser resumida en revisión bibliográfica pertinente al tema, trabajos de campo en la área de estudio y trabajos de gabinete, momento de análisis y integración de los datos obtidos, con elaboración de textos, perfiles y mapas. Delante de la metodología empleada depreendese que, malgrado los argumentos usados para creación del PEl sean, la sua mayoría, pautados en la importancia de la biodiversidad, es la geodiversidad la gran responsable por esta, debiendo, por lo tanto, ser también valorizada y divulgada.
\end{abstract}

PALABRAS-CLAVE Unidades de conservación. Aspectos bioticos y abioticos. .

\section{INTRODUÇÃO}

A geodiversidade é a base para a configuração paisagística de grande parte das unidades de conservação no Brasil; porém, na realidade o que se percebe é uma valorização da biodiversidade e poucas iniciativas voltadas à valorização e divulgação dessa vertente abiótica da natureza que é o palco para o surgimento e evolução da biodiversidade (PIEKARZ; MANOSSO; LICCARDO, 2009).

Geodiversidade é um termo relativamente recente e que tem sua origem associada à Conferência de Malvern sobre Conservação Geológica e Paisagística, realizada no Reino Unido em 1993. Seu aparecimento surge como uma tentativa de divulgação dos aspectos abióticos da natureza e também como comparação ao termo biodiversidade (BENTO; RODRIGUES, 2013). 
No entender de Nieto (2001, p. 7, tradução nossa), geodiversidade refere-se

[...] ao número e a variedade de estruturas (sedimentares, tectônicas, geomorfológicas, hidrológicas e petrológicas) e de materiais geológicos (minerais, rochas, fósseis e solos), que constituem o substrato físico natural de uma região, sobre as quais se assenta a atividade orgânica, incluindo a antrópica.

Geodiversidade está associado; portanto, a variedade de ambientes, fenômenos, processos e elementos abióticos da Terra, evidenciando tempos passados e atuais. Além disso, ela é resultado da interação de diversos fatores como as rochas, o clima, os seres vivos, entre outros, possibilitando o aparecimento de paisagens distintas em todo o mundo (BRILHA, 2005).

É um conceito análogo ao de biodiversidade, este último devendo ser compreendido como

"[...] a variabilidade de organismos vivos de todas as origens, compreendendo entre outros, os ecossistemas terrestres, marinhos e outros ecossistemas aquáticos e os complexos ecológicos de que fazem parte; compreendendo ainda a diversidade dentro de espécies, entre espécies e de ecossistemas" (MINISTÉRIO DO MEIO AMBIENTE, 2000, p. 9).

O ambiente fisiográfico engloba a geodiversidade, esta devendo ser entendida como o conjunto de todos os elementos relacionados aos aspectos geológicos, geomorfológicos e de solo, bem como suas composições, relações, propriedades e sistemas, tal como proposto inicialmente por Gray nos anos 2000 (GRAY, 2005).

O Parque Estadual do Ibitipoca, localizado na Zona da Mata, em Minas Gerais é uma unidade de conservação de grande beleza cênica que tem a geodiversidade não só como base para a biodiversidade, como para a oferta de atrativos turísticos, como cavernas, quedas d'água, praias fluviais, entre outras. Mesmo não sendo tão divulgado quanto à biodiversidade, é justamente a geodiversidade do parque a 
responsável pela formação de um mosaico de diversas tipologias de florestas, Cerrado, Campo Rupestre e Campo de Altitude (BENTO; RODRIGUES, 2013).

Diante disso, o objetivo desse estudo é apresentar uma breve caracterização dos aspectos geológicos e geomorfológicos, de forma a se compreender a riqueza dos recursos bióticos e abióticos lá existentes. Tem-se como justificativa a necessidade de se dar mais visibilidade a geodiversidade encontrada nas unidades de conservação, aproximando essa temática da sociedade que visita estas áreas, gerando uma empatia com a mesma, tal como a que já existe com a biodiversidade.

Para atingir esse objetivo esse trabalho ficou estruturado em três etapas principais, a saber:

a) Revisão bibliográfica pertinente ao tema, enfatizando os aspectos geológicos e geomorfológicos da área de estudo.

b) Trabalhos de campo na área de estudo, os quais nesta etapa da pesquisa foram fundamentais para confrontar a fundamentação bibliográfica, bem como para realizar a documentação fotográfica a partir de uma câmara fotográfica Sony Steady Shot (DSC-W320).

c) Trabalhos de gabinete para descrição da geodiversidade do parque, momento no qual se analisou qualitativamente todas as informações obtidas através da revisão bibliográfica e trabalhos de campo realizados na área de estudo.

\section{DESENVOLVIMENTO}

O contexto de criação de áreas protegidas está associado a um conjunto de fatores, dentre eles, um quadro alarmante de degradação ambiental, a pressão constante dos ambientalistas e a realização de conferências internacionais sobre a questão ambiental, sendo a Conferência das Nações Unidas para o Meio Ambiente Humano (Conferência de Estocolmo), realizada em 1972 na Suécia, uma referência no surgimento de políticas voltadas à temática ambiental (BENTO, 2014). 
Tem-se como um divisor de águas no Brasil a Lei Federal 9.985/2000, que instituiu o Sistema Nacional de Unidades de Conservação, que entende as unidades de conservação como sendo um

[...] espaço territorial e seus recursos ambientais, incluindo as águas jurisdicionais, com características relevantes, legalmente instituído pelo Poder Público, com objetivos de conservação e limites definidos, sob regime especial de administração, ao qual se aplicam garantias adequadas de proteção (Lei 9.985/2000, Art. $2^{\circ}$ ).

Existem duas categorias de unidades de conservação, como resultado da necessidade de se compatibilizar conservação e preservação ambiental, uma voltada exclusivamente para a preservação da natureza, admitindo-se apenas o uso indireto dos seus recursos naturais (Proteção Integral), e outra em que se admite o uso sustentável de parte dos recursos naturais (Uso Sustentável).

O Parque Estadual do Ibitipoca é uma unidade de conservação integral de 1488 hectares criada no ano de 1973, abrangendo parte dos municípios de Lima Duarte, Bias Fortes e Santa Rita do Ibitipoca, na Zona da Mata Mineira (Figura 1).

Figura 1: Localização do PEI

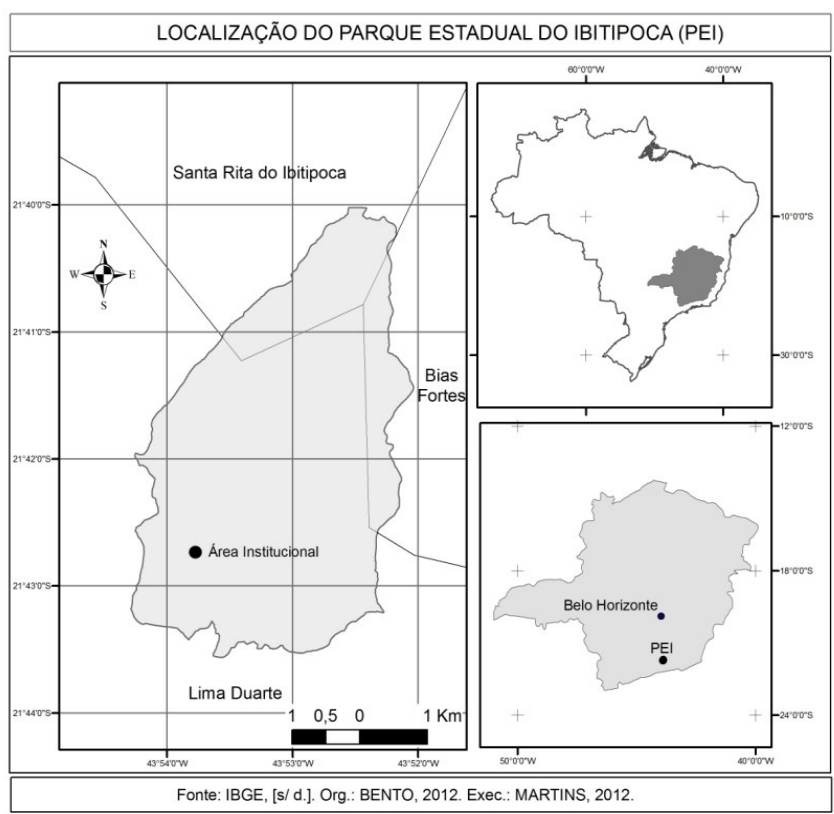

Fonte: BENTO, 2014.

O entendimento da biodiversidade desse parque está atrelado ao reconhecimento da sua geodiversidade, a qual está relacionada com a evolução 
geológica e geomorfológica a que a região foi e continua sendo submetida. Essa área está inserida numa zona de interferência entre o Cinturão Ribeira e o Brasília, tendo como domínio estrutural principal a Megassequência Andrelândia, representada por diversas sucessões de rochas metassedimentares associadas a rochas metaígneas máficas. A estratigrafia mais aceita para esse complexo foi proposta por Paciullo, Trown e Ribeiro (2003), compreendendo duas sequências estratigráficas: Carrancas e Serra do Turvo, tendo como embasamento o Complexo Mantiqueira (BENTO, 2014).

O Complexo Mantiqueira corresponde ao embasamento dos metassedimentos encontrados neste parque e é constituído, principalmente, por gnaisses e a Sequência Carrancas representa o pacote litoestratigráfico mais comum na área, com grande ocorrência de quartzitos, variando apenas o tipo de estrutura e tamanho dos grãos. Não é difícil encontrar um quartzito de granulometria grossa, conhecido localmente como sal grosso, sustentando as partes mais elevadas do parque, tais como o Pico da Lombada e Pico do Pião. Este tipo de rocha é pobre em mineral colorido e em mica, comumente constituído por aluminossilicatos, cianita, sillimanita, andaluzita e granada, apresentando foliação com orientação planar alongada (BENTO, 2014).

Em síntese, pode-se dizer que o Parque Estadual do Ibitipoca refere-se a uma área bastante deformada pelos diversos dobramentos a que foi submetida ao longo do tempo geológico, apresentando um complexo litológico em que se destacam os quartzitos, principalmente, os de granulometria grossa e estrutura planar, e o quartzito micáceo em locais pontuais, como no interior de algumas cavernas (Figuras 2 e 3 ).

Estes dobramentos fizeram com que o Parque Estadual do Ibitipoca se destacasse topograficamente em relação às áreas vizinhas, apresentando um modelado de relevo que vai do montanhoso ao escarpado, destacando o Pico da Lombada com 1784 metros de altitude (BENTO, 2014). Outro aspecto que contribui para a manutenção dessa altitude destacada são as litologias encontradas na região. O quartzito, por sua estabilidade e dureza, é mais resistente ao processo de erosão do que os gnaisses, encontrados nos arredores e em alguns locais pontualmente dentro do parque. 
Volume 10, Número 3, 2014

Biodiversidade e Unidades de Conservação

Figura 2: Amostra do quartzito de granulometria mais grossa e de cor clara

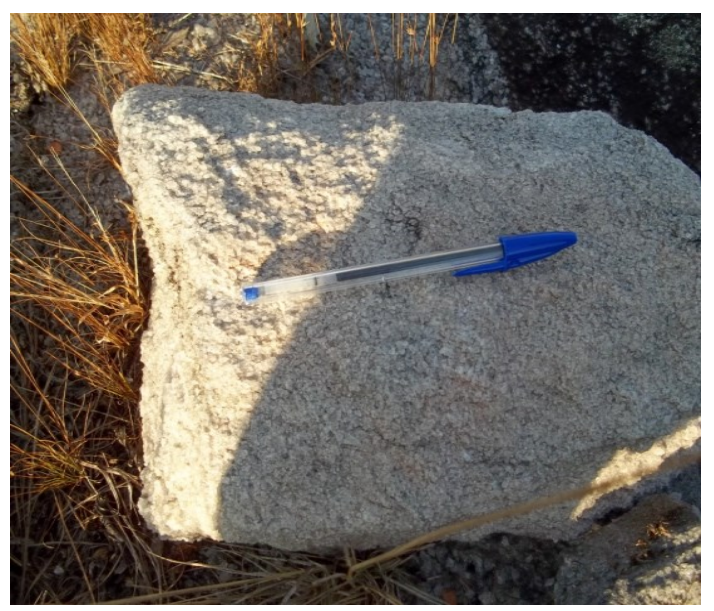

Autor: BENTO, 2012.

Figura 3: Quartzito micáceo, rico em biotita e muscovita, com tons mais coloridos como o róseo

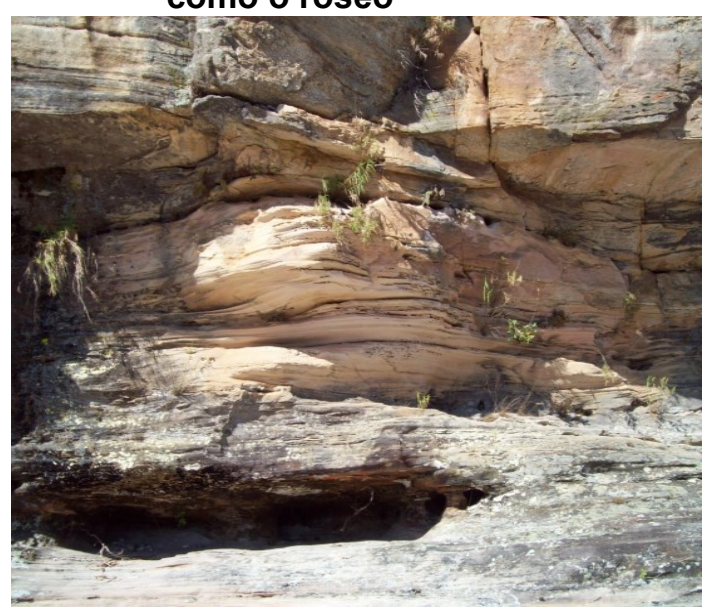

Autor: BENTO, 2012.

Além da litologia, o relevo local sofre influência do controle estrutural, que também está relacionado com o tectonismo ocorrido nesta região. Essa influência pode ser notada nas grandes linhas de falha ao longo dos cursos d'água e escarpas, nos vales encaixados, na formação das quedas d'água etc.

No Parque Estadual do Ibitipoca ocorre, portanto, devido às inter-relações entre os componentes naturais, um modelado mais escarpado na porção leste e oeste nos limites do parque, sustentado pelos quartzitos e, nas áreas mais rebaixadas, destaca-se uma superfície plana a ondulada, refletindo a diferença litológica existente. 
Esse contraste topográfico aliado às diferenças litológicas encontradas no PEI provoca, direta ou indiretamente, a ocorrência de uma grande diversidade de espécies vegetais e animais no local, o que está relacionado também com a diversidade de solos e de condições climáticas (Figura 4).

Figura 4: Mosaico com algumas formações vegetais encontradas no parque: (A) - Mata nebular com solo coberto por liquens; (B) - Campo arenoso; (C) - Cerrado de altitude; (D) Campo rupestre e (E) - Mata grande apontada ao fundo e Candeial em primeiro plano

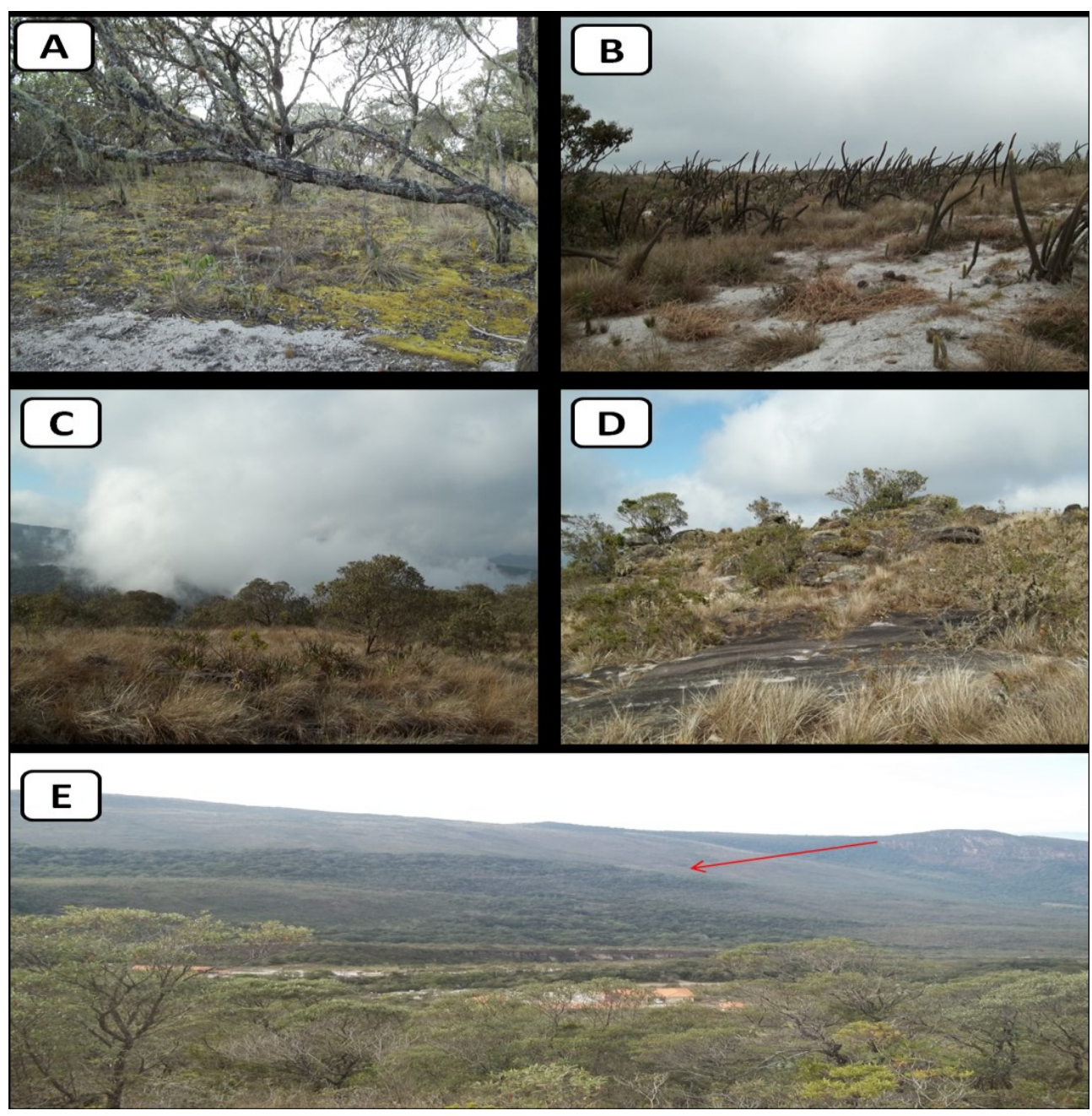

Autor: BENTO, 2012.

O clima na Serra do Ibitipoca é classificado como Tropical de Altitude Mesotérmico, apresentando inverno frio a seco e verão chuvoso, tendo temperaturas médias entre 12 a $220 \mathrm{C}$ e a pluviosidade média anual de cerca de $1.500 \mathrm{~mm}$ (DIAS, 2000). É nítida a influência da altitude, uma vez que o parque se destaca 
topograficamente em relação às áreas circunvizinhas, propiciando a formação de um ambiente mais úmido e frio, o qual, por conseguinte, condiciona o surgimento de um tipo de vegetação distinta que comporta, por sua vez, muitas espécies endêmicas (RODELA, 2010).

Quanto aos solos, estes

[...] são rasos, arenosos, pobres em nutrientes e ricos em alumínio trocável. Consequentemente, a vegetação predominante é de pequeno porte, exceto nos vales mais profundos e grotas, onde ocorre acúmulo de materiais. Somente nos solos sobre o xisto ocorrem teores mais elevados de argila, situação observada na Mata Grande onde as condições do meio físico permitiram o desenvolvimento de uma vegetação florestal de maior porte (IEF, 2007, p. 43).

As formações vegetais encontradas nessa área, tendo como referência a Lei Federal $n^{\circ} 11.428 / 2006$ que define em seu art. $2^{\circ}$ as formações vegetais que integram o Bioma Mata Atlântica, se encaixam nesse bioma, destacando-se: Floresta Ombrófila Densa Altimontana (Mata Nebular), Floresta Ombrófila Densa Montana (Mata Grande), Mata de Candeial, além das matas ciliares e de galeria. Dentre as formações campestres destacam-se os Campos de Altitude e os Campos Rupestres (BENTO, 2014).

Bento (2014) no seu estudo "PARQUE ESTADUAL DO IBITIPOCAMG: potencial geoturístico e proposta de leitura do seu geopatrimônio por meio da interpretação ambiental", traz um apanhado com as principais características da vegetação encontrada nesse parque. Segundo ela, a Mata Nebular aparece, numa escala regional, nas maiores altitudes, recebendo grande umidade em função da frequente presença de nuvens. Tem como característica principal a grande quantidade de plantas epífitas, com destaque para os liquens e as bromélias, que também são frequentes no solo. Em geral, as maiores árvores não ultrapassam os 15 metros de altura e a diversidade de espécies é pequena.

Já a Mata Grande se diferencia da Mata Nebular pelo maior porte das árvores (mais de 20 metros de altura), maior riqueza florística e por ocorrer, principalmente, em altitudes inferiores. Um aspecto específico dessa formação são as matas de grota, relacionadas com o entorno das grutas ou com as ravinas existentes em diversos 
locais do parque. As condições de umidade e de acúmulo de solo existentes no entorno destes locais propiciam o desenvolvimento de florestas.

A Mata de Candeial corresponde à formação arbórea mais característica do Parque do Ibitipoca, sendo formada quase exclusivamente pela candeia (Eremanthus erythropappus). Os candeiais ocupam uma faixa entre as bordas da floresta ombrófila e a vegetação campestre, entre altitudes de 1.000-1.600 metros, adentrando as duas formações, aonde vão reduzindo sua densidade até não mais ocorrer.

Dentre as formações campestres, os Campos de Altitude são encontrados normalmente em altitudes superiores a 1.000 metros, predominando as espécies herbáceas, gramíneas e arbustos esparsos. Já os Campos Rupestres são encontrados junto aos afloramentos quartzíticos em altitudes superiores a 1.500 metros, tendo como domínio principal as espécies herbáceo-arbustivas e eventual presença de arvoretas de até dois metros de altura.

Ao contrário da vegetação, que reflete diretamente as condições fisiográficas, no caso da fauna, a geodiversidade atua indiretamente na sua distribuição, como explicado por Romariz (2008, p. 76): “a umidade, a luz ou diversos outros fatores, que tão grande influência exercem sobre as plantas, pouco atuam sobre os animais, a não ser de forma indireta, através da vegetação".

No PEI e arredores foram registradas 14 espécies de anfíbios, sendo uma endêmica; 18 espécies de répteis; 41 espécies de mamíferos, destacando-se os primatas e diversas espécies de aves, nove das quais estão ameaçadas de extinção: Spizaetus tyrannus, Penelope obscura, Odontophorus capueira, Amazona vinacea, Macropsalis forcipata, Pteroglossus bailloni, Campephilus robustus, Pyroderus scutatus e Sicalis flaveola (IEF, 2007).

O bloco-diagrama a seguir (Figura 5) sinaliza para as inter-relações entre os elementos abióticos e bióticos do Parque Estadual do Ibitipoca. Percebe-se que nos pontos mais altos, onde o relevo caracteriza-se como escarpado a montanhoso, não há formação de solo e predomina o estrato herbáceo graminóide, com esparsos arbustos (campos rupestres). Em contrapartida, em locais de relevo escarpado, com predomínio de rocha quartzítica, há a formação de solos arenosos e mais rasos, com menor poder de retenção de água, destacando-se os campos herbáceos-graminosos 
(campos de altitude). Já em locais de relevo ondulado, que tem como substrato rochoso o xisto e/ou gnaisse são formados solos mais profundos e com maior quantidade de argila, mais favoráveis à manutenção da umidade contribuindo na geração formações mais exuberantes, como a Mata Grande. Transitando entre as formações campestres e florestais surge a Mata de Candeia, num relevo suave a forte ondulado (BENTO, 2014).

Figura 5: Bloco diagrama com os principais tipos fisionômicos da vegetação em topo-sequência do Parque Estadual do lbitipoca: Formações florestais: 1- Mata Nebular, 2- Mata Grande ao fundo e tipos de solo: A- Solo formado sobre complexo de gnaisse e xisto, B-Solo formado sobre o quartzito e C- Quartzito encontrado em grande parte da área do parque
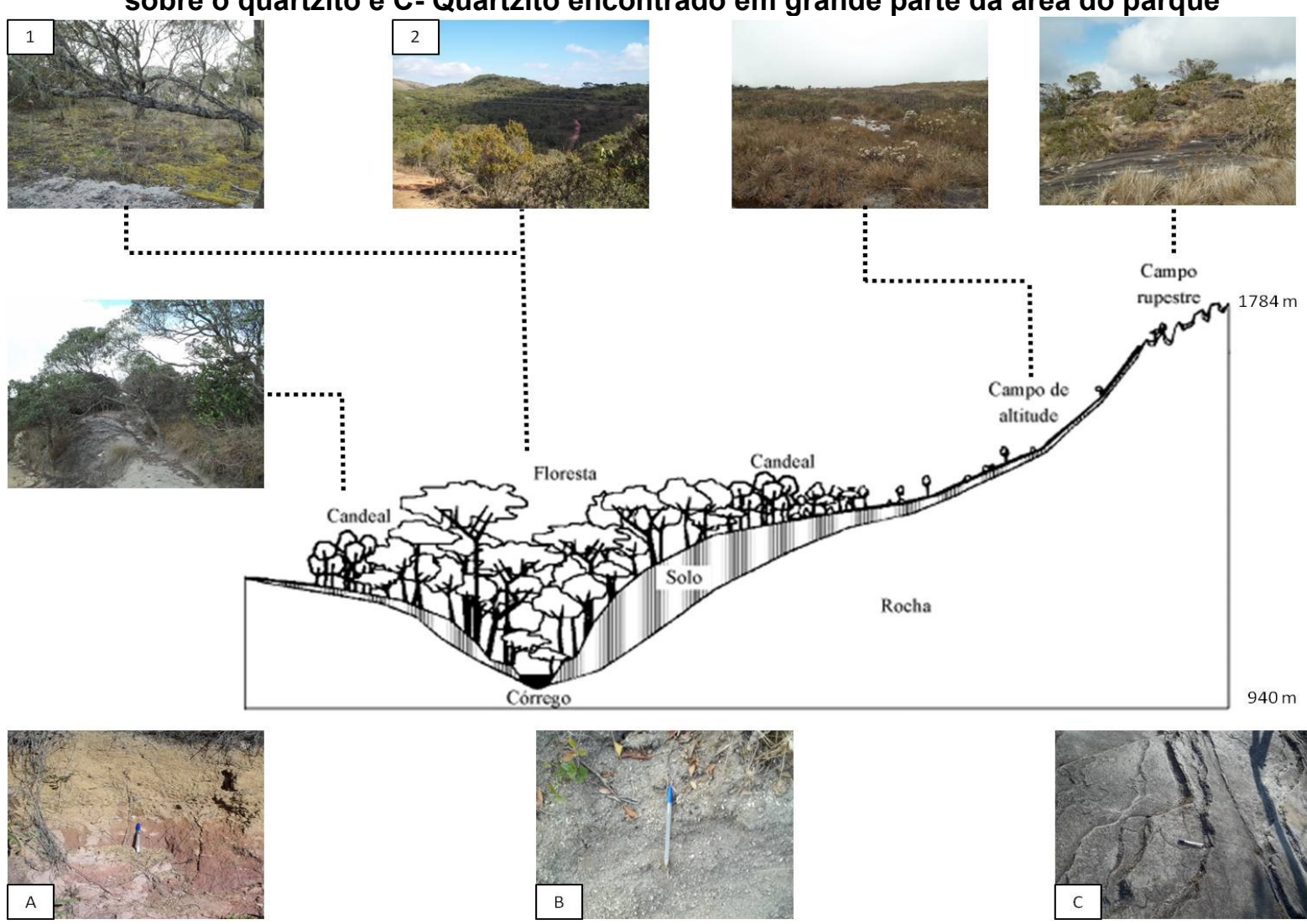

Fonte: BENTO, 2014.

Relevante ressaltar que a evolução geológica e geomorfológica proporcionou, além da abastada biodiversidade, a formação de feições e/ou geoformas de grande beleza cênica encontradas no parque, as quais, inclusive, são seus principais atrativos turísticos, como as quedas d'água, lagos, praias fluviais e as grutas. 


\section{CONCLUSÃO}

O objetivo desse trabalho foi estimular uma visão integrada da natureza, demonstrando a relação de interdependência que existe entre a biodiversidade e a geodiversidade, a partir do estudo de caso do PEI. A partir desse estudo foi possível perceber que a biodiversidade do Parque Estadual do Ibitipoca está apoiada e depende da riqueza da geodiversidade, como os tipos de rochas, relevo, solos, entre outros aspectos abióticos, todos contribuindo para a formação de uma região elevada topograficamente, com a geração de um clima mais úmido e propício a ocorrência de diferentes tipos de flora e fauna, muitos endêmicos dessa região.

Diante dessa realidade é de suma importância que essa temática seja amplamente divulgada no parque, mediante uma abordagem integrada, mostrando as inter-relações que existem na natureza, até mesmo porque, no subprograma de Interpretação Ambiental do Plano de Manejo do Parque Estadual do Ibitipoca é evidente a valorização da biodiversidade em detrimento da geodiversidade.

\section{AGRADECIMENTOS}

Agradecimentos à Coordenação de Aperfeiçoamento de Pessoal de Nível Superior (CAPES) pela bolsa de doutorado e ao Instituto Estadual de Florestas (IEF) pelo apoio à pesquisa.Parte final do artigo, na qual se apresentam as conclusões correspondentes aos objetivos e resultados.

\section{REFERÊNCIAS}

BENTO, L. C. M.; RODRIGUES, S. C. Para além da biodiversidade: em busca de uma maior valorização e divulgação da geodiversidade - Um estudo de caso do Parque Estadual do Ibitipoca/MG. MG Biota, Belo Horizonte, v. 6, n. 2, jul/set. 2013, p. 30-42.

BENTO, L. C. M. PARQUE ESTADUAL DO IBITIPOCA/MG: potencial geoturístico e proposta de leitura do seu geopatrimônio por meio da interpretação ambiental. 2014. 185 f. Tese (Doutorado em Geografia) - Instituto de Geografia, Universidade Federal de Uberlândia, Uberlândia, 2014.

BRASIL. Lei ${ }^{\circ}$ 9.985, de 18 de julho de 2000. Instituiu o Sistema Nacional de Unidades de Conservação e dá outras providências. Cadernos da Reserva da Biosfera, São Paulo, 2 ed., n. 18, 2000. 76 p. 
BRILHA, J. Patrimônio geológico e geoconservação - a conservação da natureza na sua vertente geológica. Braga: Palimage, 2005. 190 p.

BROUWN, J. H.; LOMOLINO, M. V. Biografia. 2 ed. Ribeirão Preto: FUNPEC Editora, 2006. 691 p.

DIAS, H. C. T. Geoambientes e pedogênese do Parque Estadual do Ibitipoca, Município de Lima Duarte (MG). 2000. 87P. Tese (Doutorado em Agronomia) - Programa de Pós-graduação em Solos e Nutrição de Plantas, Universidade Federal de Viçosa, Viçosa, 2000.

GRAY, M. Geodiversity and Geoconservation: what, why, and how? Geodiversity \&

Geoconservation, p. 4-12, 2005. Disponível em: <http://www.georgewright.org/223gray.pdf>. Acesso em:7 fev. 2012.

INSTITUTO ESTADUAL DE FLORESTAS. Plano de manejo do Parque Estadual do Ibitipoca. Belo Horizonte: IEF, 2007. $130 \mathrm{p}$.

MINISTÉRIO DO MEIO AMBIENTE. Convenção sobre Diversidade Biológica. Brasília: MMA, 2000. $32 \mathrm{p}$.

NIETO, L. M. Geodiversidade: propuesta de una definición integradora. Boletin geológico y minero, v. 112, n. 2, p. 3-12, 2001. Disponível em: <http://www.igmes.es/internet/Boletin/2001/112_2-2001ARTICLE\%20\%20GEODIVERSIDAD.pdf>. Acesso em: 23 jun. 2012.

PACIULLO, F. V. P.; TROWN, R. A. J.; RIBEIRO, A. Geologia da Folha Andrelândia. In: Projeto Sul de Minas - etapa I. Belo Horizonte: UFMG, 2003. p. $84-119$.

PIEKARZ, G. F.; MANOSSO, F.; LICCARDO, A. O patrimônio geológico das unidades de conservação: geoconservação e geoturismo. In: CONGRESSO BRASILEIRO DE UNIDADES DE CONSERVAÇÃO, 6., 2009, Curitiba. Anais... Curitiba: [s.n], 2009. ñ paginado.

RODELA, L. G. Relevo do Parque Estadual do Ibitipoca, Sudeste de Minas Gerais. In: COLÓQUIO DE PESQUISADORES DE TURISMO, HOSPITALIDADE, PAISAGEM E RECURSOS NATURAIS: INTEGRANDO IDÉIAS, 1., 2010, São Paulo. Anais... São Paulo: Universidade Nove de Julho, 2010, p. 225-245.

ROMARIZ, D. de A. Biogeografia: temas e conceitos. São Paulo: Scortecci, 2008. 199 p. 